\title{
CrystEngComm
}

Check for updates

Cite this: CrystEngComm, 2021, 23, 730

Received 26th August 2020,

Accepted 5th December 2020

DOI: 10.1039/d0ce01252a

rsc.li/crystengcomm

\section{Fabrication of $\mathrm{Gd}_{x} \mathrm{Fe}_{y} \mathrm{O}_{z}$ films using an atomic layer deposition-type approach $\dagger$}

\author{
Pengmei Yu, (iD ${ }^{a}$ Sebastian M. J. Beer, ${ }^{\mathrm{b}}$ Anjana Devi (DD ${ }^{\mathrm{b}}$ and Mariona Coll (iD*a
}

\begin{abstract}
The growth of complex oxide thin films with atomic precision offers bright prospects to study improved properties and novel functionalities. Here we tackle the fabrication of gadolinium iron oxide thin films by an atomic layer deposition-type approach in which iron and gadolinium tailor-made metalorganic precursors (bis( $N$-isopropyl ketoiminate)iron(I), [Fe('pki) $\left.)_{2}\right]$ and tris $\left(N, N^{\prime}\right.$-diisopropyl-2-dimethylamidoguanidinato)gadolinium(III), [Gd(DPDMG) $\left.)_{3}\right)$ are alternately reacted with ozone and deposited on silicon substrates at $250{ }^{\circ} \mathrm{C}$. The structure, chemical composition and magnetic properties of the resulting films are compared with those obtained from a commercially available ferrocene precursor $\left[\mathrm{Fe}(\mathrm{Cp})_{2}\right]$ and [Gd(DPDMG) $)_{3}$. All films resulted in cation ratio close to nominal stoichiometry with negligible amount of organic species. The tailor-made metalorganic precursors, designed to provide similar thermal behavior, result in the formation of polycrystalline $\mathrm{Gd}_{3} \mathrm{Fe}_{5} \mathrm{O}_{12}$ films coexisting with $\mathrm{GdFeO}_{3}, \mathrm{Gd}_{2} \mathrm{O}_{3}$ and $\mathrm{Fe}_{2} \mathrm{O}_{3}$ whereas the combination of $\left[\mathrm{Fe}(\mathrm{Cp})_{2}\right]$ and $\left[\mathrm{Gd}(\mathrm{DPDMG})_{3}\right]$ mainly favors the formation of $\mathrm{Gd}_{3} \mathrm{Fe}_{5} \mathrm{O}_{12}$ films coexisting with traces of $\mathrm{Gd}_{2} \mathrm{O}_{3}$. This study demonstrates that this is a viable route to prepare complex $\mathrm{Gd}_{x} \mathrm{Fe}_{y} \mathrm{O}_{z}$ films and could be used for the design of complex oxide films with improved properties upon rigorous study of the compatibility of metalorganic precursors.
\end{abstract}

\section{Introduction}

$\mathrm{GdFeO}_{3}$ and $\mathrm{Gd}_{3} \mathrm{Fe}_{5} \mathrm{O}_{12}$ are two ternary oxide systems sharing fascinating magnetic and magneto-optical properties ${ }^{1,2}$ that can open new directions in the field of spintronics and magnonics. ${ }^{3-7}$ The ability to prepare stable $\mathrm{Gd}_{x} \mathrm{Fe}_{y} \mathrm{O}_{z}$ phases with the appropriate stoichiometry, ${ }^{8,9}$ often as coatings of high aspect ratio structures, is becoming relevant to study new physics emerging from the films and at their interfaces. ${ }^{10,11}$ The best layer uniformity with atomic scale control is effectively achieved by atomic layer deposition (ALD). ${ }^{12,13}$ This is a versatile thin film deposition technique that relies on alternate pulsing of chemical precursors that react with the surface species in a self-limiting manner. Hence, the ALD process consists of a repetition of a basic sequence of reactant pulses and purges, i.e. a cyclic process. These characteristics offer exceptional control in film

\footnotetext{
${ }^{a}$ Institut de Ciéncia de Materials de Barcelona (ICMAB-CSIC), Campus de la UAB, 08193 Bellaterra, Barcelona, Spain. E-mail: mcoll@icmab.es; Tel: +34 935801853 ${ }^{b}$ Inorganic Materials Chemistry, Ruhr University Bochum, Universitätsstraße 150, Bochum 44801, Germany

$\dagger$ Electronic supplementary information (ESI) available: List of $\mathrm{Fe}$ and Gd precursors tested by ALD to prepare $\mathrm{Fe}_{2} \mathrm{O}_{3}$ and $\mathrm{Gd}_{2} \mathrm{O}_{3}$, respectively. EDX spectra of as-deposited films, summary of the composition and thickness of $\mathrm{Gd}_{2} \mathrm{O}_{3}$, $\mathrm{Fe}_{2} \mathrm{O}_{3}$ and $\mathrm{Gd}_{x} \mathrm{Fe}_{y} \mathrm{O}_{z}$. XPS Survey spectra of $\mathrm{Gd}_{3} \mathrm{Fe}_{5} \mathrm{O}_{12}$ films and the magnetic measurements $(M(H)$ and $M(T))$ for the $\mathrm{Gd}_{x} \mathrm{Fe}_{y} \mathrm{O}_{z}$ films. See DOI: 10.1039/ d0ce01252a
}

composition and thickness and excellent step coverage over complex structures. This is a well-established technique to deposit binary compounds ${ }^{14-16}$ and its unique deposition characteristics motivates the continuous research to develop deposition process for compositions with increased complexity. ${ }^{17}$ Unfortunately, the ALD synthesis of a ternary oxide is, in most of the cases, not a simple addition of the corresponding binary oxide processes. ${ }^{18,19}$ The compatibility of different chemical precursors confined under similar deposition conditions together with a varying surface species after every precursor dose increase considerably the level of intricacy. ${ }^{17,20,21}$ Indeed, $\mathrm{LaFeO}_{3},{ }^{18} \mathrm{La}_{1-x} \mathrm{Sr}_{x} \mathrm{FeO}_{3}$ (ref. 18) and $\mathrm{ErFeO}_{3}$ (ref. 22) are some of the few examples reported on ALD rare-earth ferrites deposited by alternate pulsing of one reactant per component of the complex oxide. More recently, epitaxial $\mathrm{GdFeO}_{3}$ films have been grown by alternate dosing of a single heterobimetallic precursor, already containing the stoichiometric $1: 1$ cation ratio, and ozone. ${ }^{23}$

Clearly, the development of $\mathrm{Gd}_{x} \mathrm{Fe}_{y} \mathrm{O}_{z}$ phases by ALD will require knowledge on the synthetic path which strongly depends on the chemistry of the metalorganic precursors. In this study we are interested in exploring the opportunities that the chemistry of homometallic Gd and Fe compounds can offer to grow Gd-Fe-oxide thin films by an ALD-type approach. To this end, a special focus has to be laid to the compatibility of $\mathrm{Fe}$ and Gd precursors in terms of reactivity, volatility and thermal stability ${ }^{24,25}$ as the commonly used 
precursors for these elements do not have matching properties. While there is a rich variety of suitable iron precursors based on cyclopentadienyl, halide, $\beta$-diketonate and acetylacetonate ligands, see Table $\mathrm{S} 1, \uparrow$ there are limited sources for Gd mainly involving silylamide, $\beta$-diketonate and cyclopentadienyl-based ligand systems, see Table S2.† Among these precursors, we investigate the use of the cost-efficient and commercially available ferrocene precursor, $\left[\mathrm{Fe}(\mathrm{Cp})_{2}\right]$, in which the metal is bonded to two $\eta^{5}$-cyclopentadienyl rings exhibiting a high thermal stability, versus the use of $\operatorname{bis}(\mathrm{N}$ isopropyl ketoiminate)iron(II), $\left[\mathrm{Fe}\left({ }^{\mathrm{i}} \mathrm{pki}\right)_{2}\right],{ }^{26}$ which possesses a ketoiminate ligand with mixed nitrogen and oxygen donors providing reactivity and stability, respectively. Their reactivity is evaluated against tris $\left(N, N^{\prime}\right.$-diisopropyl-2-dimethylamidoguanidinato)gadolinium(III), $\left[\mathrm{Gd}(\mathrm{DPDMG})_{3}\right]^{27}$ which is a fully nitrogen coordinated complex and possesses an enhanced reactivity due to the rare-earth nitrogen bonds, see Scheme 1.

First, we have studied the reactivity of each homo-metallic precursor with $\mathrm{H}_{2} \mathrm{O}$ and $\mathrm{O}_{3}$ to grow the corresponding binary oxides and identify the compatible deposition conditions for the subsequent ternary oxide system. By means of X-ray diffraction (XRD), atomic force microscopy (AFM), X-ray photoelectron spectroscopy (XPS) and Rutherford backscattering spectrometry/nuclear reaction analysis (RBS/ NRA), the phase purity, crystallinity, surface morphology and chemical composition of the grown complex compounds have been examined. Finally, the magnetic properties have been evaluated by superconducting quantum interference device (SQUID) magnetometry.

\section{Experimental}

\subsection{Thin film deposition}

The $\mathrm{Gd}_{x} \mathrm{Fe}_{y} \mathrm{O}_{z}$ thin films deposition was carried out in a Savannah 100 ALD system from Cambridge NanoTech Inc. P-type boron-doped $\mathrm{Si}(100)$ and $\mathrm{SiO}_{2} / \mathrm{Si}(100)$ substrates were purchased from Active Business Company GmbH. Before introduction into the ALD chamber, the substrates were cleaned with acetone and ethanol followed by nitrogen gas blow drying. Prior to film growth, all substrates were kept in a constant high purity nitrogen flow for $10 \mathrm{~min}$ and subsequently exposed to ozone pulses to form a hydroxyl-terminated surface. Precursor sources were pulsed into the reaction chamber separated in

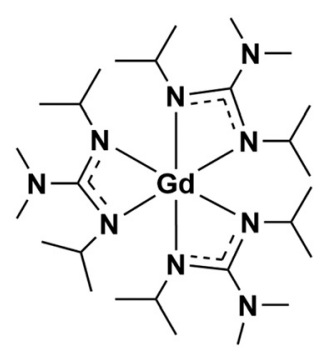

(a)

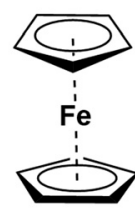

(b)

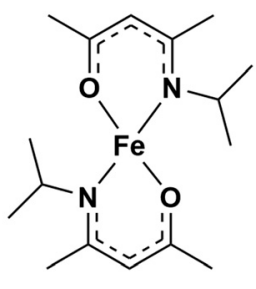

(c)
Scheme 1 Molecular structure of the Gd and Fe precursors studied in this work: (a) [Gd(DPDMG) $)_{3}$, (b) $\left[\mathrm{Fe}(\mathrm{Cp})_{2}\right]$, (c) [Fe('pki) $\left.)_{2}\right]$. time and purged by high purity nitrogen with a gas flow between $40-70 \mathrm{sccm}$. Ozone $\left(\mathrm{O}_{3}\right)$ and Milli-Q water $\left(\mathrm{H}_{2} \mathrm{O}\right)$ were considered as oxygen sources. $\mathrm{O}_{3}$ was produced and delivered upon use from an LG-7 Corona discharge ozone generator with a $5 \mathrm{wt} \%$ concentration and an output of $5 \mathrm{~g} \mathrm{~h}^{-1}$. The generator was modulated to work at $5 \mathrm{~V}$ direct current voltage with an adjusted flow of $0.18 \mathrm{~L} \mathrm{~min}^{-1}$. The metalorganic precursors, $\left[\mathrm{Gd}(\mathrm{DPDMG})_{3}\right]$ and $\left[\mathrm{Fe}\left({ }^{\mathrm{i}} \mathrm{pki}\right)_{2}\right]$ were synthesised as reported ${ }^{27,26}$ and handled under inert conditions, while the commercial $\mathrm{Fe}$ precursor $\left[\mathrm{Fe}(\mathrm{Cp})_{2}\right]$ or ferrocene, (bis(cyclopentadienyl)iron (98\% purity)), was purchased from Sigma-Aldrich and utilized as received. In this study we utilized three different valving systems that are here identified as flow mode (F), pressure-boost (PB) and exposure mode (E), scheme shown in Fig. S1. $\dagger$ F consists in having a continuous flow of inert gas to carry the precursor to the reaction chamber. For low-vapor pressure precursors, PB is used. That is, before precursor pulses, the gas exit valve was closed and ALD valve opened to allow carrier gas filling up the precursor cylinder and resulting in an elevated pressure in it. Afterwards, the exit valve is opened and the chamber pressure recovered, followed by precursor pulsing along with the filled nitrogen into the chamber. Under certain circumstances, E was applied. In this case, the gas exit valve was closed, exposing the sample to the precursor prolonged time to promote surface reaction and saturation over larger areas. Post-deposition thermal treatments, were performed on selected samples in an oxidising atmosphere (oxygen, $0.3 \mathrm{~L} \mathrm{~min}^{-1}$ flow) in a tubular furnace at $450-900{ }^{\circ} \mathrm{C}$ for $30-90$ minutes.

Gadolinium oxide from [Gd(DPDMG) $)_{3}$. The deposition of gadolinium oxide was investigated in a chamber temperature range between 160 and $250{ }^{\circ} \mathrm{C}$ with the $\left[\mathrm{Gd}(\mathrm{DPDMG})_{3}\right]$ precursor heated at $120-135{ }^{\circ} \mathrm{C}$. Based on the work of Milanov et al., ${ }^{28}$ the Gd pulse/purge/oxidant pulse/purge duration was adapted in our reactor in the following sequence for $\mathrm{H}_{2} \mathrm{O} 3 \mathrm{~s} / 20 \mathrm{~s} / 1 \mathrm{~s} / 10 \mathrm{~s}$ and for $\mathrm{O}_{3} 3 \mathrm{~s} / 20 \mathrm{~s} / 0.2 \mathrm{~s} /$ $7 \mathrm{~s}$.

Iron oxide from $\left[\mathrm{Fe}(\mathrm{Cp})_{2}\right]$. The deposition process of iron oxide from $\left[\mathrm{Fe}(\mathrm{Cp})_{2}\right]$ was explored between the deposition temperature range of $150-250{ }^{\circ} \mathrm{C}$ with $\left[\mathrm{Fe}(\mathrm{Cp})_{2}\right]$ heated at 90 ${ }^{\circ} \mathrm{C}$. The Fe pulse/purge/oxidant pulse/purge doses were $2 \mathrm{~s} / 4$ $\mathrm{s} / 1 \mathrm{~s} / 10 \mathrm{~s}$ for $\mathrm{H}_{2} \mathrm{O}$ and $2 \mathrm{~s} / 4 \mathrm{~s} / 0.2 \mathrm{~s} / 7 \mathrm{~s}$ for $\mathrm{O}_{3}$. Longer pulse/ purge lengths of $\left[\mathrm{Fe}(\mathrm{Cp})_{2}\right](5 \mathrm{~s} / 10 \mathrm{~s})$ and $\mathrm{O}_{3}(0.3 \mathrm{~s} / 11 \mathrm{~s})$ were investigated in the ternary oxide films as specified in the corresponding section.

Iron oxide from [ $\left.\mathbf{F e}\left({ }^{\mathrm{i}} \mathbf{p} \mathbf{k i}\right)_{2}\right]$. The deposition temperature of iron oxide from $\left[\mathrm{Fe}\left({ }^{\mathrm{i}} \mathrm{pki}\right)_{2}\right]$ was also evaluated between $150-$ $250{ }^{\circ} \mathrm{C}$ with the $\left[\mathrm{Fe}\left({ }^{\mathrm{i}} \mathrm{pki}\right)_{2}\right]$ kept at $100-130{ }^{\circ} \mathrm{C}$. Based on the work of Peeters et al., ${ }^{26}\left[\mathrm{Fe}\left({ }^{\mathrm{i}} \mathrm{pki}\right)_{2}\right], \mathrm{H}_{2} \mathrm{O}$ and $\mathrm{O}_{3}$ were pulsed/ purged by 8 s/10 s, 4 s/10 s and 0.2 s/10 s, respectively.

\subsection{Thin film characterization}

Qualitative elemental film composition studies were performed by energy disperse X-ray spectroscopy (EDX) employing a FEI Quanta 200 FEG microscope. Each spectrum was collected with $15 \mathrm{keV}$ working voltage, 3.0 spot size for 
an acquisition time of 100 s. Quantitative compositional studies were carried out using X-ray photoelectron spectroscopy (XPS) using a SPECS PHOIBOS 150 hemispherical $\mathrm{X}$-ray photoelectron spectroscopy analyser (Al Ka source, from SPECS GmbH, Berlin, Germany). The samples were analyzed with a pass energy of $10 \mathrm{eV}$ at a base pressure of $1 \times 10^{-10}$ mbar, taking a step size of $0.05 \mathrm{eV}$ and $1 \mathrm{eV}$ for the highresolution and survey spectra, respectively. The acquired spectra were interpreted with CasaXPS software for binding energy determination and element assignment after spectrum calibration with C 1s reference peak at $284.8 \mathrm{eV}$.

Thin film phase purity and crystallinity were investigated by X-ray diffraction (XRD) in the range of $2 \theta=20-80^{\circ}$ by grazing-incidence X-ray diffraction (GIXRD) at the incident angle of $1{ }^{\circ} \mathrm{C}$. Specific samples were analyzed by $\theta-2 \theta$ scan on a Bruker D8 Discover A25 diffractometer with $\mathrm{Cu} \mathrm{K \alpha}$ radiation $(\mathrm{K} \alpha=1.5406 \AA)$. The film texture was further evaluated with GADDS (General Area Detector Diffraction System) Bruker AXS, Inc equipped with a 2D detector.

The film thickness was extracted from X-ray reflectivity (XRR) measurements using a SIEMENS D5000 diffractometer and fitted using ReMagX software. ${ }^{29}$ It was further validated with spectroscopic ellipsometry (SE) measurements using a GES5E Ellipsometer from SOPRA Optical Platform. The measurements were carried out in reflection mode with variant light incident angles $\left(65-75^{\circ}\right)$ at $30^{\circ}$ analyzer angle for a spectral range of 200-900 $\mathrm{nm}$. Thin film surface morphology was assessed from atomic force microscope topographic images, $5 \mu \mathrm{m} \times 5 \mu \mathrm{m}$ in size using a Keysight 5100 microscope and further processed with Mountains®8 software.

The magnetic properties were probed by a Quantum Design MPMS-XL magnetometer based on a superconducting quantum interference device (SQUID). In-plane magnetization-temperature curve $(M(T))$ at 5 kOe and magnetic hysteresis loop $(M(H))$ at $50 \mathrm{~K}$ were explored.

Additional film composition and depth profiles were obtained from Rutherford backscattering spectrometry (RBS) coupled with nuclear reaction analysis (NRA). The experiments were carried out in the RUBION, the Central Unit for Ion Beams and Radionuclides at Ruhr University Bochum. For the measurements, a $2.0 \mathrm{MeV}{ }^{4} \mathrm{He}^{+}$beam with an intensity of 20-40 nA (tilt angle $7^{\circ}$ ) was used. The backscattered particles were detected at an angle of $160^{\circ}$ by a Si detector with a resolution of $16 \mathrm{keV}$. NRA measurements were carried out with a ${ }^{2} \mathrm{H}^{+}$beam $(1 \mathrm{MeV})$. The samples were tilted at an angle of $7^{\circ}$. The emitted protons were detected at an angle of $135^{\circ}$ with respect to the beam axis. The detector covered a solid angle of $23 \mathrm{msrad}$ and was shielded by a 6 $\mu \mathrm{m} \mathrm{Ni}$ foil to eliminate elastically scattered deuterons. Typical beam currents on the samples were close to $40 \mathrm{nA}$ in an area of $\sim 1 \mathrm{~mm}$ in diameter, whereas the collected beam charge for a sample was $12 \mu \mathrm{C}$. The RBS/NRA data were analyzed by means of the SIMNRA program suite. ${ }^{30}$ Since the detection limit of RBS is restricted especially for light atomic mass elements, NRA is used to detect $\mathrm{C}, \mathrm{N}$ and $\mathrm{O}$ in thin film material. The calculation of the atomic percentages is achieved through the integration of the detected counts per area (in order of magnitudes of $10^{15}$ at $\mathrm{cm}^{-2}$ ). It must be considered that the total counts are logically lower for thin samples. Hence, not only the statistic error of the crosssection of the beam has an influence on the calculation of $\mathrm{N}$ and $\mathrm{C}$, but also the subtraction of the background measurement (bare $\mathrm{Si}(100)$ substrate in our case) is required for the NRA analysis. Therefore an error margin of approximately 3 at\% can be expected for $\mathrm{C}, \mathrm{N}$ and $\mathrm{O}$.

\section{Results and discussion}

Prior to study the deposition of ternary oxides, it is necessary to study the independent binary oxide processes, i.e. gadolinium oxide and iron oxide. The optimization procedure includes choice of oxidant co-reactants, precursor sublimation temperature, deposition temperature, carrier gas flow and valving system (flow, pressure boost, exposure described in the Experimental section), to identify the compatible conditions to finally assess the deposition of the multicomponent $\mathrm{Gd}_{x} \mathrm{Fe}_{y} \mathrm{O}_{z}$ system.

\section{1 $\mathrm{Gd}_{2} \mathrm{O}_{3}$ films}

The deposition of gadolinium oxide from $\left[\mathrm{Gd}(\mathrm{DPDMG})_{3}\right]$ was studied in our reactor according to previous work. ${ }^{28}$ The viability of ozone versus water as co-reactant was investigated in the deposition range of $160-250{ }^{\circ} \mathrm{C}$ with $40 \mathrm{sccm} \mathrm{N}_{2}$ gas for 500 cycles under flow mode. The precursor sublimation temperature was optimized to $135^{\circ} \mathrm{C}$ and the use of pressure boost to enhance its sublimation was evaluated. The use of water as co-reactant did not result in the deposition of gadolinium, regardless of the valving system. On the other hand, combining $\left[\mathrm{Gd}(\mathrm{DPDMG})_{3}\right]$ with pressure boost, with ozone at $250{ }^{\circ} \mathrm{C}$, Gd was detected in the films, Fig. S2. $\dagger$ The corresponding AFM topographic image illustrates high degree of film density, surface uniformity with a root mean square (RMS) roughness value below $1 \mathrm{~nm}$, Fig. $1 \mathrm{a}$.

Phase formation and degree of crystallinity of a $30 \mathrm{~nm}$ thick film was studied by GIXRD at the as-deposited stage and after different post annealing treatments (700-900 ${ }^{\circ} \mathrm{C}, 30$ min in oxygen atmosphere), see Fig. 1b. The absence of Bragg reflections in the as-deposited step suggests the formation of amorphous films. The same patterns were obtained after post annealing treatments up to $900{ }^{\circ} \mathrm{C}$, suggesting that the films remain amorphous. From RBS/NRA analysis the chemical composition of the film was studied in detail to rule out the presence of impurities trapped in the film that could hinder the crystallization process, ${ }^{31,32}$ see Fig. 1c. In the RBS profile it can be distinguished the $\mathrm{Gd}$ peak and the $\mathrm{O}$ peak superimposing the Si signal. Note that the tailing of the $\mathrm{Si}$ edge and the tailing of the Gd signal to lower energies indicate a diffusion of $\mathrm{Gd}$ and $\mathrm{Si}$ at the interface. This phenomenon can be explained with the tendency of rareearth to form silicates and silicides at such interfaces, ${ }^{33}$ and could contribute to the poor crystallinity of the films in 

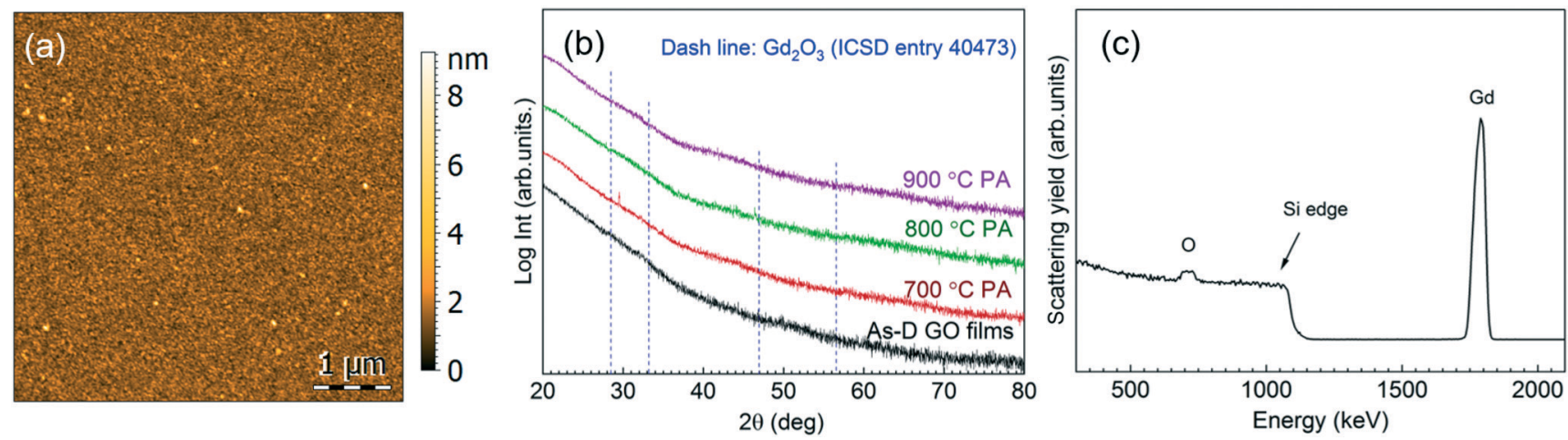

Fig. 1 (a) AFM topographic image of an as-deposited sample from [Gd(DPDMG) ${ }_{3}$ and $\mathrm{O}_{3}$ at the deposition temperature of $250{ }^{\circ} \mathrm{C}$. (b) GIXRD spectra of the as-deposited (As-D) and post-annealed (PA) films $\left(700-900^{\circ} \mathrm{C}\right)$. (c) RBS profile of the $800^{\circ} \mathrm{C}$ post-annealed sample.

Fig. 1b. RBS/NBA quantification, Table $\mathrm{S} 3, \dagger$ reveals a low nitrogen and oxygen content of 0.4 at $\%$ and $<3 \%$, respectively. Note that the $\mathrm{Gd} / \mathrm{O}$ ratio is 0.30 evidencing an oxygen overstoichiometry. Similar observations have been recently reported in ALD iron oxide films and attributed to the prolonged ozone exposure. ${ }^{34}$

To evaluate the deposition homogeneity across a $4 " \mathrm{Si}$ wafer using $\left[\mathrm{Gd}(\mathrm{DPDMG})_{3}\right]$, the film thickness was analyzed at six different locations by means of XRR, see Fig. S3. $\dagger$ The areal thickness map was built in which the $x$ axis corresponds to the gas flow pathway in the chamber, the $y$ axis is the direction perpendicular to the flow, while $z$ axis corresponds to the film thickness. As the wafer size is similar to the diameter of the ALD chamber, at $x=0 \mathrm{~cm}$ one can find the gas inlet whereas at $x=10 \mathrm{~cm}$ sits the gas outlet. For 40 sccm flow, Fig. 2a, the maximum thickness achieved is near the gas inlet and decreases along with the gas pathway inlet. This areal thickness gradient can result from insufficient gas flow, a leak upstream of the precursor or inadequate purge times. ${ }^{35}$ By increasing the gas flow to $70 \mathrm{sccm}$, the thickness homogeneity is improved although the areal gradient is still observed, Fig. 2b. Finally, longer precursor exposure to the reaction surface along with longer purging times (exposure mode) was explored but the amount of Gd deposited was below the EDX and XRR detection limit. This behavior suggests that prolonged exposure of $\left[\mathrm{Gd}(\mathrm{DPDMG})_{3}\right]$ at $250{ }^{\circ} \mathrm{C}$ does not favor a saturation growth model either.

From deposition at $250{ }^{\circ} \mathrm{C}$ and $70 \mathrm{sccm}$ gas flow, a growth per cycle (GPC) of $\sim 0.6 \AA$ per cycle is obtained near the inlet. Similar growth rates are reported when combined $\mathrm{Gd}(\mathrm{thd})_{3} /$ $\mathrm{O}_{3}$ (ref. 36) although higher growth rates have been reported when using N-bonded Gd precursors and water $(1 \AA$ per cycle). ${ }^{27}$ It is very likely that the use of $\mathrm{O}_{3}$ and $\mathrm{N}$-containing ligands can form intermediate $\mathrm{NO}_{x}$ and $\mathrm{C}-\mathrm{O}$ species ${ }^{37}$ resulting in a more complex surface reaction mechanism affecting the growth rate. ${ }^{31}$

According to this study, the selected $\mathrm{Gd}_{2} \mathrm{O}_{3}$ deposition conditions for further studies were selected: $T_{\mathrm{Gd}-\text { subl }}=135{ }^{\circ} \mathrm{C}$ and pressure boost, $T_{\text {dep }}=250{ }^{\circ} \mathrm{C}, 70 \mathrm{sccm} \mathrm{N}_{2}$ carrier gas flow and ozone as co-reactant. Note that experimental conditions here reported do not lead to a self-limiting surface reaction.

\section{2 $\mathrm{Fe}_{2} \mathrm{O}_{3}$ films}

There is a divergence of deposition conditions reported for the preparation of $\mathrm{ALD} \mathrm{Fe}_{2} \mathrm{O}_{3}$ from ferrocene. ${ }^{34,35,38-40}$ One
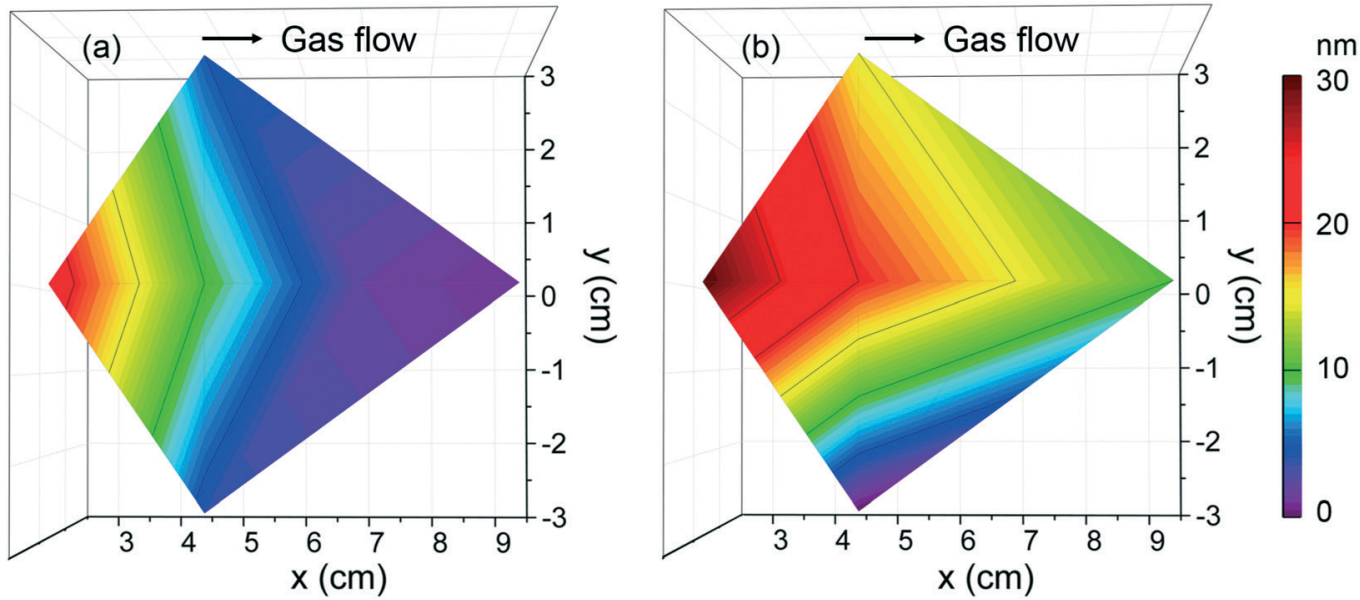

Fig. 2 Thickness mappings of $\mathrm{Gd}_{2} \mathrm{O}_{3}$ films grown at (a) $40 \mathrm{sccm}$ and (b) $70 \mathrm{sccm} \mathrm{N}$ flow located at different positions of a 4 " Si wafer in the ALD chamber. Deposition conditions: $T_{\text {dep }}=250^{\circ} \mathrm{C}$ with ozone using PB mode, 500 cycles. 
main purpose of our study is to investigate the feasibility of $\left[\mathrm{Fe}(\mathrm{Cp})_{2}\right]$ to react with $\mathrm{H}_{2} \mathrm{O}$ or $\mathrm{O}_{3}$ to form $\mathrm{Fe}_{2} \mathrm{O}_{3}$ in our reactor and to evaluate its compatibility with the $\left[\mathrm{Gd}(\mathrm{DPDMG})_{3}\right]$ precursor.

The deposition of $\left[\mathrm{Fe}(\mathrm{Cp})_{2}\right]$ was studied in the $160-250{ }^{\circ} \mathrm{C}$ temperature window in flow mode $(70 \mathrm{sccm})$ repeating 2000 cycles, Fig. S4.† Fe was only detected when ozone was used as co-reactant for a temperature range of $200-250{ }^{\circ} \mathrm{C}$. The 15 $\mathrm{nm}$ as-deposited films $\left(250{ }^{\circ} \mathrm{C}\right)$ present a mesh-like surface morphology with a surface RMS roughness of $3 \mathrm{~nm}$, Fig. 3a, and crystallize into the $\alpha-\mathrm{Fe}_{2} \mathrm{O}_{3}$ phase (ICSD entry 24004), Fig. 3b. EDX spectrum of an as-deposited film is shown in Fig. 3c.

According to the deposition conditions identified above, the thickness homogeneity along a 4 " silicon wafer was investigated using $\left[\mathrm{Fe}(\mathrm{Cp})_{2}\right]$ and ozone at $250{ }^{\circ} \mathrm{C}$ at $70 \mathrm{sccm}$, Fig. 4a. The maximum thickness, $15 \mathrm{~nm}$, is identified towards the gas outlet revealing an evident thickness gradient. To improve the $\mathrm{Fe}_{2} \mathrm{O}_{3}$ deposition homogeneity, exposure mode was adopted enabling ferrocene and ozone to stay longer period of time in the chamber and promote surface saturation. In this case, an average thickness of 20 $\mathrm{nm}$ was obtained across the whole Si wafer, Fig. 4b. The resulting GPC is $\sim 0.1 \AA$ per cycle, significantly lower than the reported GPC values when combined $\left[\mathrm{Fe}(\mathrm{Cp})_{2}\right]$ and $\mathrm{O}_{3}\left(0.6^{-}\right.$ $1.4 \AA$ per cycle). ${ }^{39,40}$ Schneider et $a l^{34}$ recently reported that lower growth per cycles at $250{ }^{\circ} \mathrm{C}$ can be assigned to increased decomposition of ozone.

From this study the suitable processing conditions identified for $\mathrm{Fe}_{2} \mathrm{O}_{3}$ using ferrocene are $T_{\mathrm{Fe} \text {-subl }}=90{ }^{\circ} \mathrm{C}, T_{\text {dep }}$ $=250{ }^{\circ} \mathrm{C}$ with ozone as co-reactant under $70 \mathrm{sccm} \mathrm{N}_{2}$ gas and exposure mode, which could be compatible with those previously found for the $\left[\mathrm{Gd}(\mathrm{DPDMG})_{3}\right]$ precursor.

The suitability of the ketoiminate iron precursor $\left[\mathrm{Fe}\left({ }^{\mathrm{i}}-\right.\right.$ pki $\left.)_{2}\right],{ }^{26}$ to deposit $\mathrm{Fe}_{2} \mathrm{O}_{3}$ films was evaluated and compared to the commercial $\left[\mathrm{Fe}(\mathrm{Cp})_{2}\right]$ and to $\left[\mathrm{Gd}(\mathrm{DPDMG})_{3}\right]$.

Based on the previous studies on $\left[\mathrm{Fe}\left({ }^{\mathrm{i}} \mathrm{pki}\right)_{2}\right],{ }^{26}$ the iron precursor was sublimed at $100{ }^{\circ} \mathrm{C}$ (with and with no pressure boost) in the temperature window of $150-250{ }^{\circ} \mathrm{C}$ using $\mathrm{H}_{2} \mathrm{O}$ or $\mathrm{O}_{3}$ as co-reactant under $70 \mathrm{sccm} \mathrm{N}_{2}$ gas flow for 2000 cycles. Based on EDX studies, no iron was detected at any of these processing conditions, see Fig. S5a.t Therefore, the sublimation temperature of $\left[\mathrm{Fe}\left({ }^{\mathrm{i}} \mathrm{pki}\right)_{2}\right]$ was increased up to $130{ }^{\circ} \mathrm{C}$ and the processing conditions were re-evaluated. Depositing $\mathrm{Fe}_{2} \mathrm{O}_{3}$ using $\left[\mathrm{Fe}\left({ }^{\mathrm{i}} \mathrm{pki}\right)_{2}\right]$ and $\mathrm{O}_{3}$ at $250{ }^{\circ} \mathrm{C}$ resulted in a $65 \mathrm{~nm}$ film, Fig. S5b and c. $\dagger$ AFM analysis on asdeposited films reveals a dense and homogeneous surface with very low surface roughness (RMS $\sim 1 \mathrm{~nm}$ ), Fig. 5a. The crystallinity of $65 \mathrm{~nm} \mathrm{Fe}_{2} \mathrm{O}_{3}$ films was investigated by GIXRD. In the as-deposited stage, the films are amorphous. Subsequent post thermal treatments for $30 \mathrm{~min}$ in oxygen at $500{ }^{\circ} \mathrm{C}$ and at $800{ }^{\circ} \mathrm{C}$ did not favor the crystallization of $\mathrm{Fe}_{2} \mathrm{O}_{3}$. However, typical peaks of $\alpha-\mathrm{Fe}_{2} \mathrm{O}_{3}$ were observed at $900{ }^{\circ} \mathrm{C}$, Fig. 5b. It can be seen from the RBS analysis, Fig. $5 \mathrm{c}$, that distribution of $\mathrm{Fe}$ and $\mathrm{O}$ is homogeneous throughout the film thickness with a ratio of $\mathrm{Fe}$ to $\mathrm{O}$ of 0.52 and $\mathrm{C}$ and $\mathrm{N}$ abundance below $<0.8 \%$ indicating a clean surface reaction and desorption of byproducts during the growth of $\mathrm{Fe}_{2} \mathrm{O}_{3}$ (see Table S3†). Fig. 6 shows the film thickness homogeneity along the 4 " silicon wafer. In this case, a thickness gradient from $65 \mathrm{~nm}$ to $45 \mathrm{~nm}$ was identified, showing a preferred deposition near the gas inlet, similar to the $\mathrm{Gd}_{2} \mathrm{O}_{3}$. Accordingly, the preferred conditions for $\mathrm{Fe}_{2} \mathrm{O}_{3}$ deposition from $\left[\mathrm{Fe}\left({ }^{\mathrm{i}} \mathrm{pki}\right)_{2}\right]$ using an ALD-type approach is: $T_{\mathrm{Fe}-\text { subl }}=130$ ${ }^{\circ} \mathrm{C}, T_{\text {dep }}=250{ }^{\circ} \mathrm{C}$, ozone as co-reactant at $70 \mathrm{sccm} \mathrm{N}_{2}$ flow.

The resultant growth rate of iron oxide films is $\sim 0.4 \AA$ per cycle, which is more than four times higher than that from $\left.\left[\mathrm{Fe}(\mathrm{Cp})_{2}\right]\left(0.1 \AA \text { per cycle). The higher GPC of [Fe( }{ }^{\mathrm{i}} \mathrm{pki}\right)_{2}\right]$ could be attributed to the enhanced reactivity from the mixed $\mathrm{N}-\mathrm{O}$ ligand chemistry ${ }^{26,41}$ compared to the stable Fe-metallocene bonding in $\left[\mathrm{Fe}(\mathrm{Cp})_{2}\right] .{ }^{39}$ The steric hindrance of the ligands will also play a key role. The low reactivity of Cp can certainly slow the reaction mechanism when compared to the ketoiminate ligands. ${ }^{42-44}$ This difference in precursor chemistry also affects the surface morphology of the final film noting that $\left[\mathrm{Fe}\left({ }^{\mathrm{i}} \mathrm{pki}\right)_{2}\right]$ leads to smooth and dense films whereas $\left[\mathrm{Fe}(\mathrm{Cp})_{2}\right]$ favors higher degree of porosity (Fig. 3a).

The optimal deposition conditions for each binary oxide are summarized in Table 1. Along with the difference in GPC of $\left[\mathrm{Fe}(\mathrm{Cp})_{2}\right]$ compared to $\left[\mathrm{Gd}(\mathrm{DPDMG})_{3}\right]$ and $\left[\mathrm{Fe}\left({ }^{\mathrm{i}} \mathrm{pki}\right)_{2}\right]$
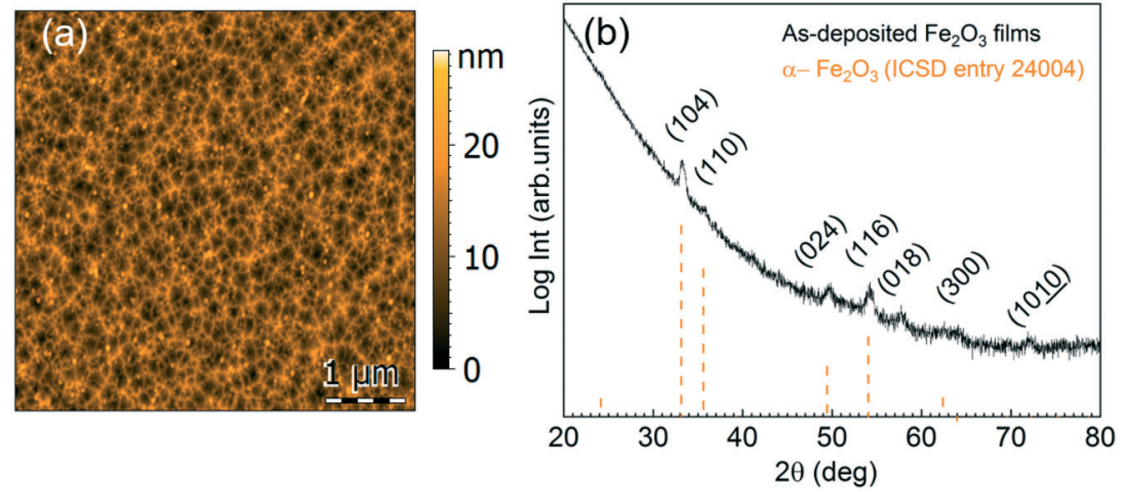

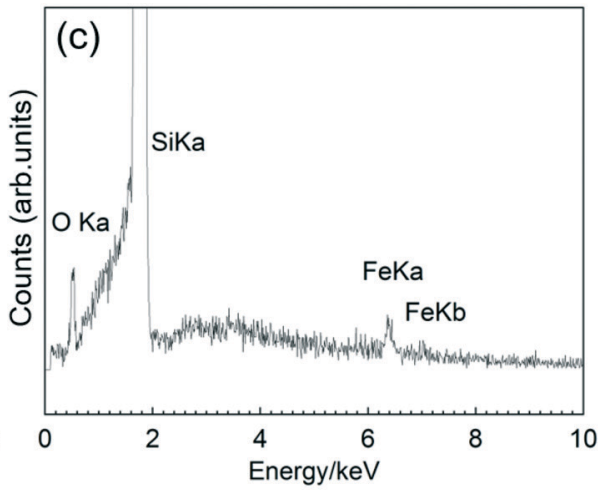

Fig. 3 (a) $5 \mu \mathrm{m} \times 5 \mu \mathrm{m}$ AFM topography image from the as-deposited $15 \mathrm{~nm}$ film prepared from $\left[\mathrm{Fe}(\mathrm{Cp})_{2}\right]$ and ozone at $T_{\text {dep }}=250{ }^{\circ} \mathrm{C}$, (b) corresponding GIXRD pattern. (c) EDX spectrum showing $\mathrm{Fe}$ in the deposited films. 

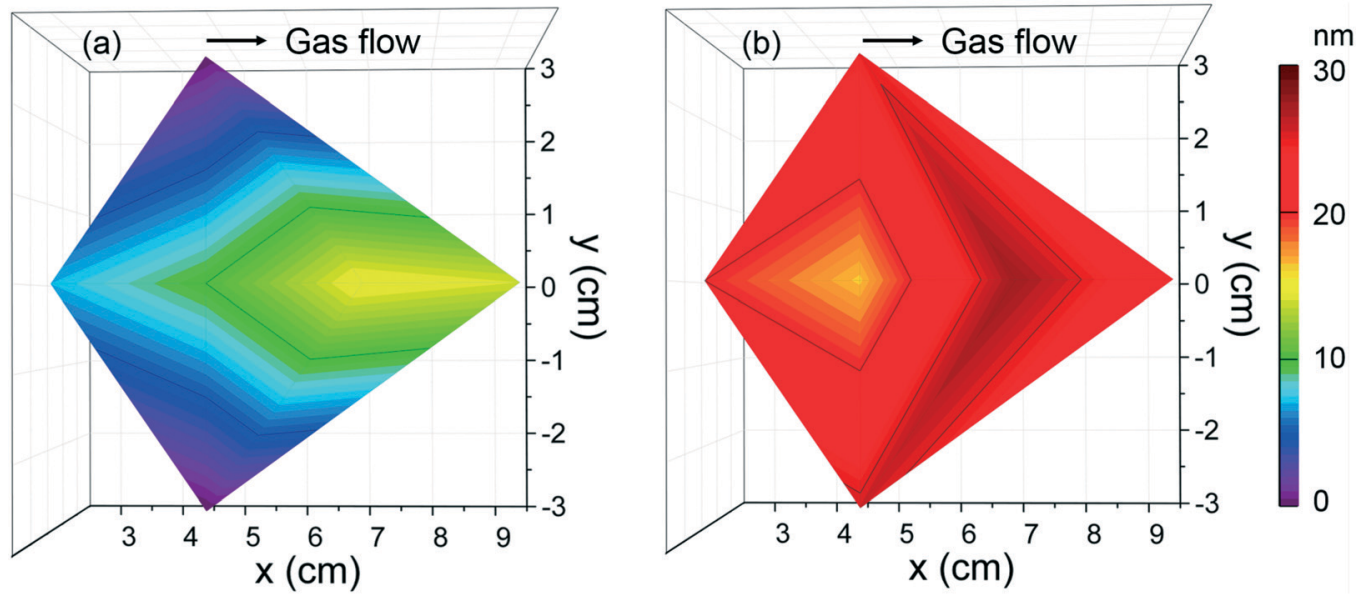

Fig. 4 Thickness mappings of $\mathrm{Fe}_{2} \mathrm{O}_{3}$ films deposited from $\left[\mathrm{Fe}(\mathrm{Cp})_{2}\right]$ and $\mathrm{O}_{3}$ at $T_{\text {dep }}=250{ }^{\circ} \mathrm{C}, 2000$ cycles at (a) flow mode and (b) exposure mode with $70 \mathrm{sccm} \mathrm{N}$ gas.
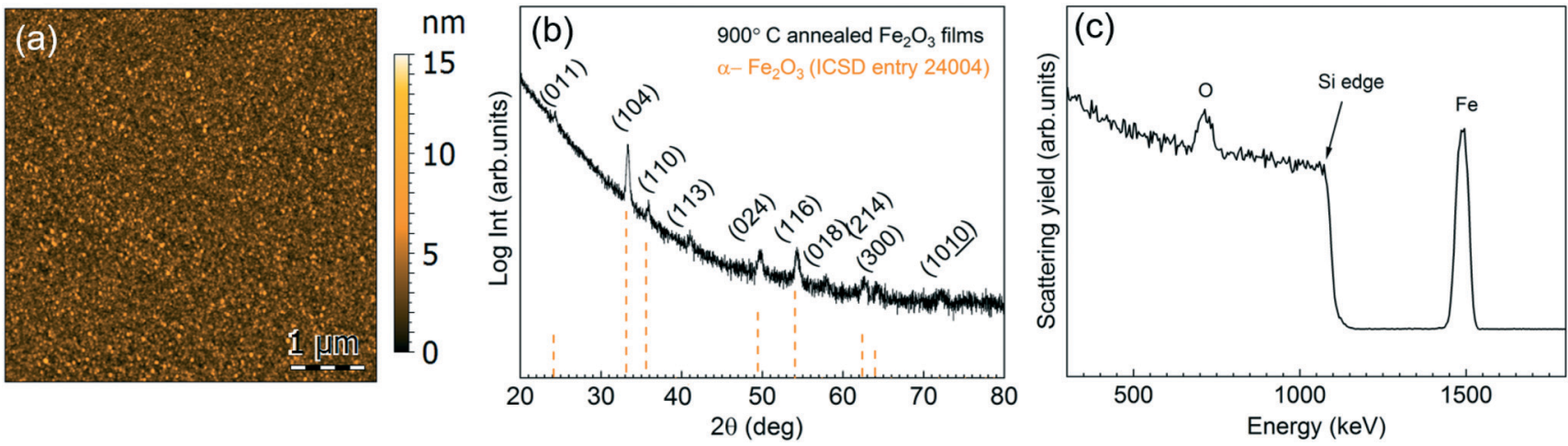

Fig. 5 Characteristics of the $\mathrm{Fe}_{2} \mathrm{O}_{3}$ films prepared by alternate pulsing of [Fe('pki) $)_{2}$ (in pressure boost mode) and ozone at $250{ }^{\circ} \mathrm{C}$. (a) $\mathrm{AFM}$ topographic image of the as-deposited $\mathrm{Fe}_{2} \mathrm{O}_{3}$ films, (b) GIXRD spectrum of a $900{ }^{\circ} \mathrm{C}$ annealed sample, (c) $\mathrm{RBS}$ spectrum of the Fe $\mathrm{O}_{3}$ annealed at $800{ }^{\circ} \mathrm{C}$.

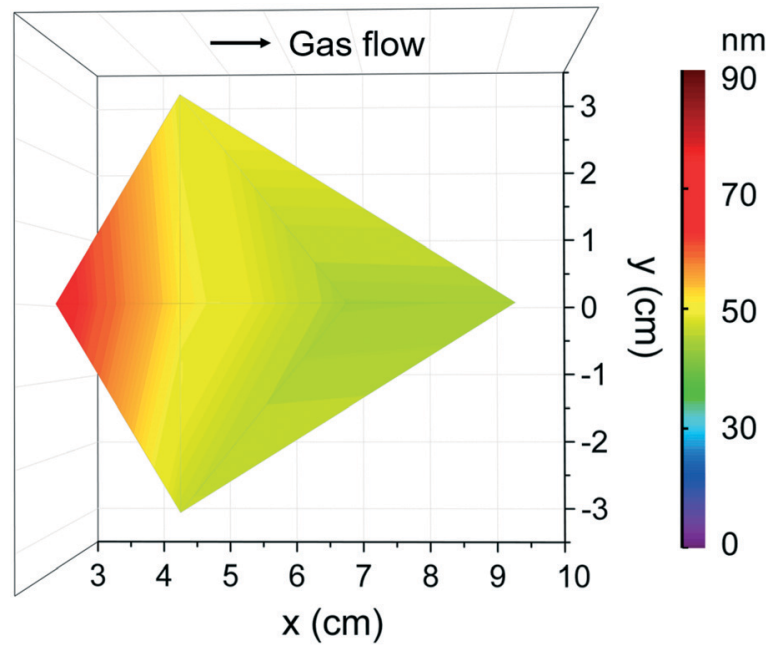

Fig. 6 Thickness homogeneity map of $\mathrm{Fe}_{2} \mathrm{O}_{3}$ films that are located at various chamber positions on a 4 " Si wafer from $\left[\mathrm{Fe}\left({ }^{(} \mathrm{pki}\right)_{2}\right]$ and $\mathrm{O}_{3}$ under $70 \mathrm{sccm}$ flow at $T_{\text {dep }}=250^{\circ} \mathrm{C}$ with 2000 cycles. already mentioned above, distinct thickness homogeneity along the silicon wafer was detected (Fig. 2b, 4b and 6). [Fe( ${ }^{i}-$ pki $)_{2}$ ] and [Gd(DPDMG $\left.)_{3}\right]$ showed a clear trend to be deposited near the gas inlet, whereas $\left[\mathrm{Fe}(\mathrm{Cp})_{2}\right]$ resulted in a highly homogeneous distribution. This discrepancy could also arise from the pronounced reactivity of the $\left[\mathrm{Gd}(\mathrm{DPDMG})_{3}\right]$ and $\left[\mathrm{Fe}\left({ }^{\mathrm{i}}-\right.\right.$ $\mathrm{pki}_{2}$ ] precursors containing $\mathrm{N}$ - and $\mathrm{O}-$ metal bonds which are prone to be depleted at the reaction chamber inlet. ${ }^{28}$

It is important to consider the differences observed between the three metal oxides to elaborate the deposition process of the ternary systems. Importantly, when combining the different reactants, i.e. Fe-precursor, Gd-precursor and $\mathrm{O}_{3}$, the active surface sites will differ from the studied binary system and therefore differences in the reactivity, composition and film crystallinity might be expected. ${ }^{20}$

\section{3 $\mathrm{Gd}_{x} \mathrm{Fe}_{y} \mathrm{O}_{z}$ system}

The deposition of the $\mathrm{Gd}_{x} \mathrm{Fe}_{y} \mathrm{O}_{z}$ system was first assessed by studying the combination of $\left[\mathrm{Gd}(\mathrm{DPDMG})_{3}\right]$ and $\left[\mathrm{Fe}(\mathrm{Cp})_{2}\right]$ with ozone at $250{ }^{\circ} \mathrm{C}$. The deposition process was designed by alternating nanolaminates of the respective oxides and the 
Table 1 Selected ALD recipes for Gd-O and Fe-O deposition

\begin{tabular}{|c|c|c|c|c|c|c|}
\hline & $T_{\text {dep }}\left({ }^{\circ} \mathrm{C}\right)$ & $T_{\text {subl }}\left({ }^{\circ} \mathrm{C}\right)$ & Flow (sccm) & Co-reactant & Mode & Growth rate (̊̊ per cycle) \\
\hline $\mathrm{Fe}-\mathrm{O}$ from $\left[\mathrm{Fe}(\mathrm{Cp})_{2}\right]$ & 250 & 90 & 70 & $\mathrm{O}_{3}$ & Exposure & 0.1 \\
\hline $\mathrm{Fe}-\mathrm{O}$ from $\left[\mathrm{Fe}\left({ }^{\mathrm{i}} \mathrm{pki}\right)_{2}\right]$ & 250 & 130 pressure-boost & 70 & $\mathrm{O}_{3}$ & Flow & 0.4 \\
\hline
\end{tabular}

Table $2 \mathrm{Gd}_{x} \mathrm{Fe}_{y} \mathrm{O}_{z}$ deposition conditions varying $\mathrm{Gd}-\mathrm{O} / \mathrm{Fe}-\mathrm{O}$ subcycle ratios and sequence combining $\left[\mathrm{Gd}(\mathrm{DPDMG})_{3}\right]$ and $\left[\mathrm{Fe}(\mathrm{Cp})_{2}\right]$. Estimated $\mathrm{Gd}$ and Fe at\% from EDX analysis

\begin{tabular}{|c|c|c|c|c|c|c|}
\hline GFO-Cp-1 & 10 & 50 & $1: 5$ & $\mathrm{Gd}: \mathrm{Fe}$ & 92 & 8 \\
\hline GFO-Cp-2 $2^{a}$ & 10 & 10 & $1: 1$ & $\mathrm{Gd}: \mathrm{Fe}$ & 71 & 29 \\
\hline
\end{tabular}

${ }^{a}$ Samples with $\left[\mathrm{Fe}(\mathrm{Cp})_{2}\right] 5 \mathrm{~s}$ pulse/10 s purge.
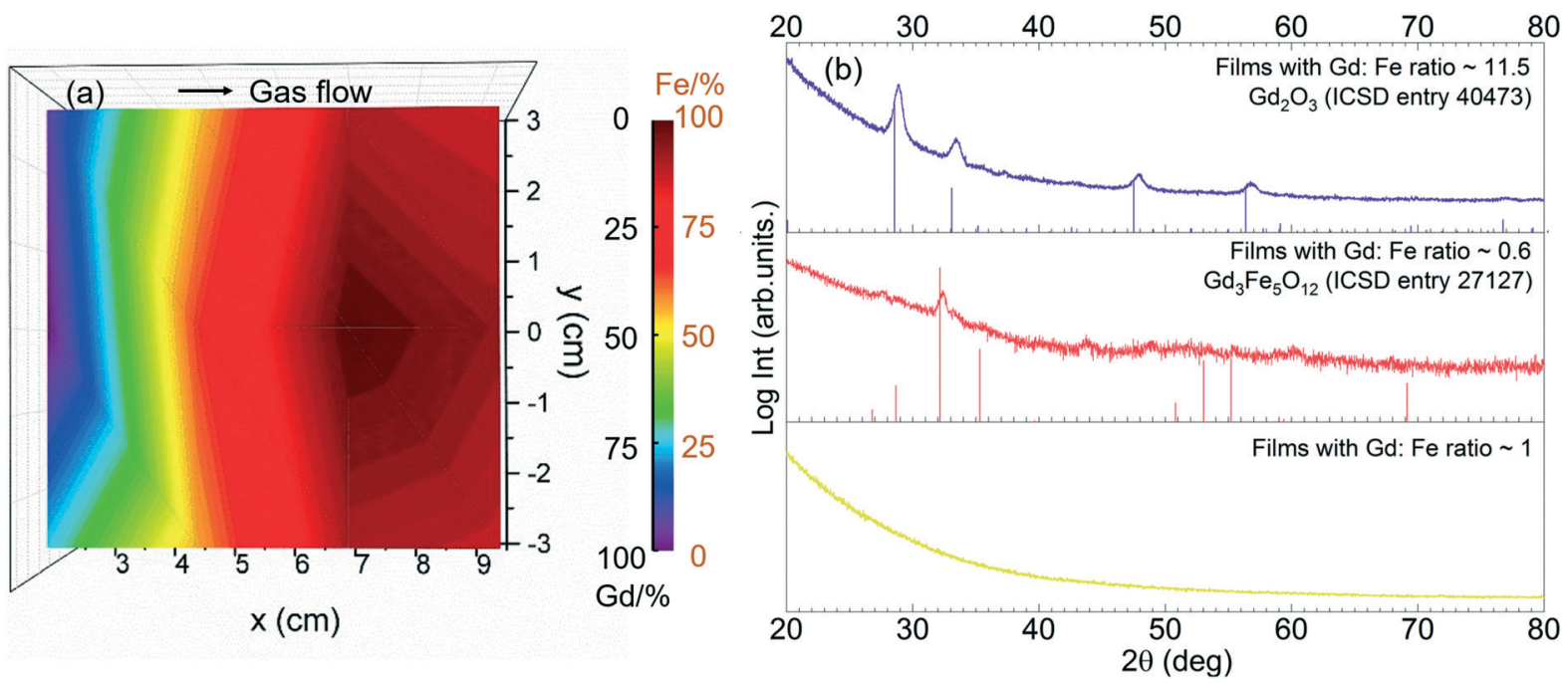

Fig. 7 (a) Elemental distribution map of $\mathrm{Gd}_{x} \mathrm{Fe}_{y} \mathrm{O}_{z}$ films under GFO-Cp-3 conditions. The ALD process was carried out using [Gd(DPDMG) 3 , $\left[\mathrm{Fe}(\mathrm{Cp})_{2}\right]$ and $\mathrm{O}_{3}$ at the deposition temperature of $250^{\circ} \mathrm{C}$. (b) GIXRD spectra of post-annealed Gd-Fe-O samples from [Fe(Cp) $)_{2}$ and [Gd(DPDMG) ${ }_{3}$ ] which are $\mathrm{Gd}: \mathrm{Fe}=11.5, \mathrm{Gd}: \mathrm{Fe}=0.6$ and $\mathrm{Gd}: \mathrm{Fe}=1$. Reference XRD patterns from $\mathrm{Gd}_{2} \mathrm{O}_{3}$, and $\mathrm{Gd}_{3} \mathrm{Fe}_{5} \mathrm{O}_{12}$ are displayed under each panel.

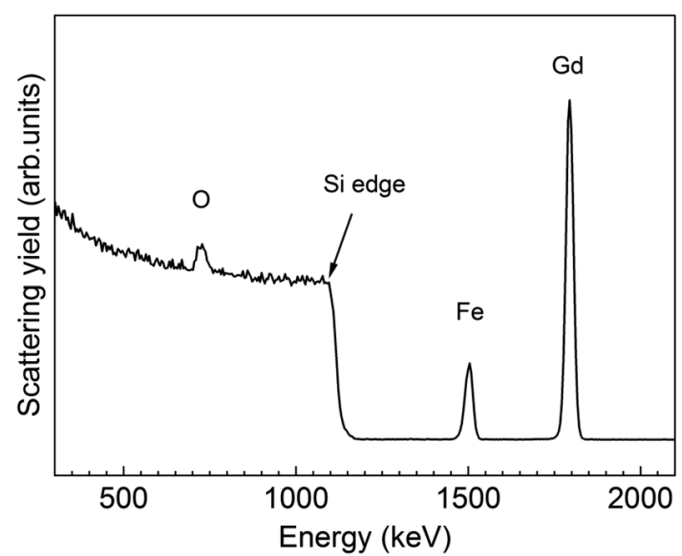

Fig. 8 RBS profile spectrum of a $30 \mathrm{~nm}$ thick $\mathrm{Gd}_{3} \mathrm{Fe}_{5} \mathrm{O}_{12}$ film annealed at $800{ }^{\circ} \mathrm{C}$ for $30 \mathrm{~min}$ in oxygen. influence of subcycle ratio and sequence were evaluated on both film stoichiometry and spatial distribution. Subsequently, the impact of post thermal treatments on phase crystallization were also studied. Table 2 lists the investigated ALD subcycle ratio and sequence along with the experimental cation ratios found by EDX analysis. According to the GPC identified in the binary oxides study $(0.6 \AA$ per cycle for $\mathrm{Gd}-\mathrm{O}$ and $0.1 \AA$ per cycle for $\mathrm{Fe}-\mathrm{O}$ ), a process with larger proportion of $\mathrm{Fe}-\mathrm{O}$ subcycles over $\mathrm{Gd}-\mathrm{O}$ subcycles was designed. Nonetheless, from this approach the amount of Gd found in the film largely exceeds that of Fe (GFO-Cp-1). In an attempt to increase the $\mathrm{Fe}$ content in the film while minimizing larger bilayer periods, ferrocene pulse and purge length were increased to $5 \mathrm{~s} / 10 \mathrm{~s}$ and the superlattice ratio decreased to 10:10 (GFO-Cp-2) which results in the intended increase of Fe content (28\%). The number of Cp and DPDMG ligands that react at the $\mathrm{Gd}-\mathrm{O}$ and $\mathrm{Fe}-\mathrm{O}$ terminated surfaces, 

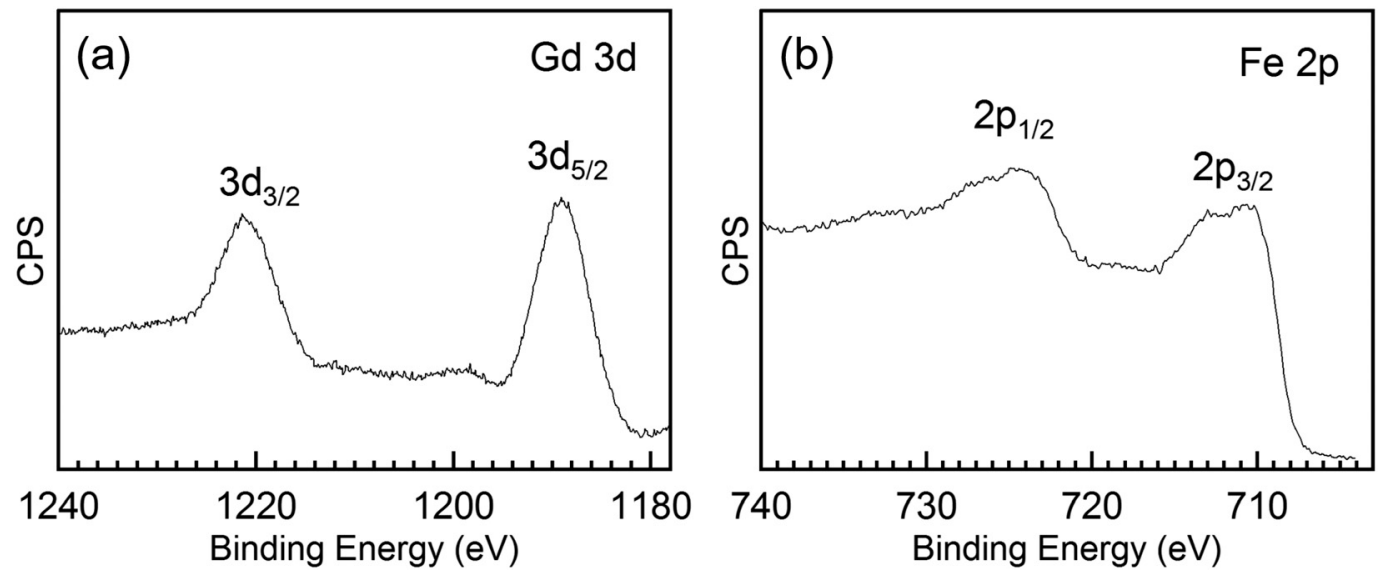

Fig. 9 (a) Gd $3 d$ core level and (b) Fe $2 p$ core level spectra of a $30 \mathrm{~nm}$ thick $\mathrm{Gd}_{3} \mathrm{Fe}_{5} \mathrm{O}_{12}$ film annealed at $800{ }^{\circ} \mathrm{C}$ for $30 \mathrm{~min}$ in oxygen.

Table $3 \mathrm{Gd}_{x} \mathrm{Fe}_{y} \mathrm{O}_{z}$ deposition varying $\mathrm{Gd}-\mathrm{O} / \mathrm{Fe}-\mathrm{O}$ subcycle ratios or sequence combining [Gd(DPDMG) $\left.)_{3}\right]$ and $\left[\mathrm{Fe}(\text { 'pki) })_{2}\right]$. Cation atomic percentages are obtained from EDX

\begin{tabular}{|c|c|c|c|c|c|c|}
\hline Sample & Gd-O subcycles & Fe-O subcycles & Theoretical ratio & Subcycle sequence & Gd (\%) & $\mathrm{Fe}(\%)$ \\
\hline GFO-Ki-2 & 2 & 1 & $2: 1$ & Fe: Gd & 50 & 50 \\
\hline
\end{tabular}
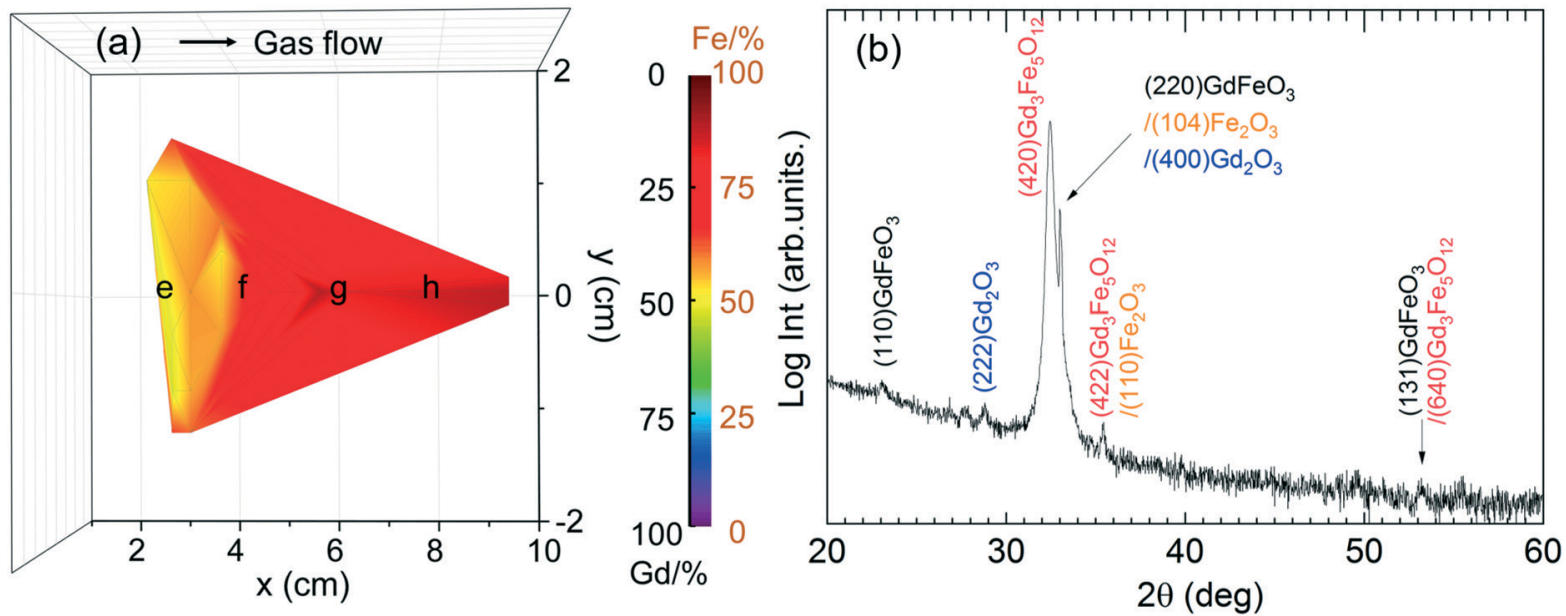

Fig. 10 (a) $\mathrm{Gd} / \mathrm{Fe}$ map of $\mathrm{Gd}_{x} \mathrm{Fe}_{y} \mathrm{O}_{z}$ films from $2 \mathrm{Gd}$ : 1 Fe deposition process combining [Gd(DPDMG) $)_{3}$ and [Fe('pki) $)_{2}$ ]. (b) XRD $\theta-2 \theta$ scan of a $800{ }^{\circ} \mathrm{C}$ annealed $120 \mathrm{~nm}$ thick Gd-Fe-O thin films with Gd/Fe ratio $\sim 1$ prepared from [Gd(DPDMG) ${ }_{3}$ ] and $\left[\mathrm{Fe}\left({ }^{(} \mathrm{pki}\right)_{2}\right]$ at $250{ }^{\circ} \mathrm{C}$.

respectively, is very likely to differ from the binary oxide system and therefore the nucleation scenario changes. Decrease in the growth rate of the mixture ${ }^{18,45}$ or even etching of the metal-O surface by the precursor ligands may occur. $^{46}$ Then, by keeping a theoretical 10:10 supercycle ratio while changing the sequence from $\mathrm{Gd}-\mathrm{O} / \mathrm{Fe}-\mathrm{O}$ to $\mathrm{Fe}-\mathrm{O} / \mathrm{Gd}-\mathrm{O}$ (sample GFO-Cp-3), the experimental cation ratio went to 49 : 51 revealing that the sequence of nanolaminates deposition has also a critical role on cation incorporation. It is likely that $\mathrm{Si}-\mathrm{OH}$ surface are preferred nucleation sites for ferrocene compared to $\mathrm{Gd}-\mathrm{O}$ terminated surface to activate the growth.
The Gd and Fe distribution along a 4" silicon wafer was investigated by EDX repeating the recipe GFO-Cp-3. The compositional map reveals that Gd is mostly located near the gas inlet (left side of the map), Fig. 7a, following the same trend observed for the binary $\mathrm{Gd}_{2} \mathrm{O}_{3}$ process (Fig. 2). Taking advantage of this spatial $\mathrm{Gd} / \mathrm{Fe}$ distribution, samples located at three different regions of the chamber corresponding to $\mathrm{Gd} / \mathrm{Fe}$ ratio of $11.5,0.6$ and 1 were investigated by GIXRD analysis, Fig. 7b. In the as-deposited stage, all films turned out to be amorphous (not shown). Then, these three samples were exposed to a post annealing process at $800{ }^{\circ} \mathrm{C}$ under 0.3 $\mathrm{L} \mathrm{min}^{-1}$ oxygen flow for $30 \mathrm{~min}$. Gd-Rich films $(\mathrm{Gd} / \mathrm{Fe}=11.5)$ 


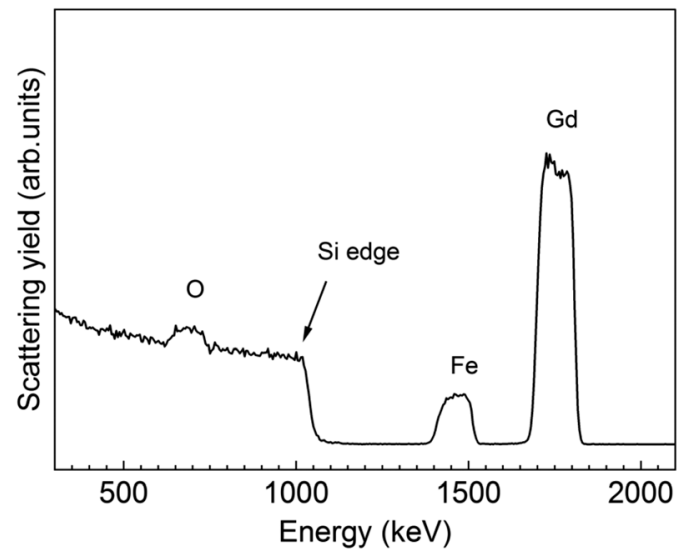

Fig. 11 RBS profile spectrum of a $120 \mathrm{~nm}$ thick $\mathrm{Gd}_{x} \mathrm{Fe}_{y} \mathrm{O}_{z}$ film annealed at $800^{\circ} \mathrm{C}$ in oxygen.

show the characteristic Bragg reflections corresponding to the cubic $\mathrm{Gd}_{2} \mathrm{O}_{3}$ phase (ICSD entry 40473). For the $\mathrm{Gd} / \mathrm{Fe}=$ 0.6 sample, the formation of crystalline $\mathrm{Gd}_{3} \mathrm{Fe}_{5} \mathrm{O}_{12}$ (garnet) film is obtained (ICSD entry 27127) with minor traces of $\mathrm{Gd}_{2} \mathrm{O}_{3}$. These films present an homogeneous surface morphology defined by fine grain size $(50 \mathrm{~nm})$ and very smooth surface showing rms of $0.7 \mathrm{~nm} \pm 0.1 \mathrm{~nm}$, see Fig. S6. $\dagger$ Finally, for the $\mathrm{Gd} / \mathrm{Fe}=1$ sample, the film remains amorphous. Therefore, gadolinium orthoferrite has not been stabilized under these conditions.

To further investigate the chemical composition and cation valence state of the post annealed $\mathrm{Gd}_{3} \mathrm{Fe}_{5} \mathrm{O}_{12}$ sample, RBS and XPS studies were performed. From the RBS spectrum of the $\mathrm{Gd}_{3} \mathrm{Fe}_{5} \mathrm{O}_{12}$ film post annealed at $800{ }^{\circ} \mathrm{C}, \mathrm{O}, \mathrm{Gd}$ and $\mathrm{Fe}$ are present, superimposed to the signal from the silicon substrate, see Fig. 8. The elemental composition of $\mathrm{Gd}, \mathrm{Fe}$ and $\mathrm{O}$ has been determined from RBS/NRA and listed in Table S3. $\uparrow$ The Gd/Fe/O amount is $12.4 / 17.6 / 67.6$ in at\% close to the ideal $\mathrm{Gd}_{3} \mathrm{Fe}_{5} \mathrm{O}_{12}$ stoichiometry. Also, $\mathrm{C}$ and $\mathrm{N}$ content remain below $2 \%$ revealing once more that the reactivity of the precursor towards ozone is sufficient to ensure a clean reaction of the surface species with desorption of the organics. On the other hand, from XPS analysis (survey spectrum shown in Fig. S7†) of the Gd 3d and Fe $2 p$ core level spectra were investigated to elucidate the oxidation state, Fig. 9a and b respectively. For Gd 3d core level spectra, main peaks of $3 \mathrm{~d}_{3 / 2}$ and $3 \mathrm{~d}_{5 / 2}$ were found at $1221.1 \mathrm{eV}$ and $1189.1 \mathrm{eV}$, respectively. These values are slightly shifted to higher binding energy than the ones reported, yet the spin-orbit splitting energy difference $\Delta E_{\mathrm{Gd} 3 \mathrm{~d}_{32}-\mathrm{Gd} 3 \mathrm{~d}_{5 / 2}}$ is $32.0 \mathrm{eV}$, in good agreement with the average value $32.1 \pm 0.3 \mathrm{eV}$ for $\mathrm{Gd}^{3+}$ containing compounds ${ }^{47}$ therefore confirming the $\mathrm{Gd}^{3+}$ oxidation number, see Table S4 $\uparrow$ For Fe 2p, the peaks appearing at $\sim 725.0 \mathrm{eV}$ and $711.4 \mathrm{eV}$ coincide with $2 \mathrm{p}_{1 / 2}$ and $2 \mathrm{p}_{3 / 2}$ doublets. The Fe $2 \mathrm{p}_{3 / 2}$ peak position and $\Delta E_{2 \mathrm{p}_{12}-2 \mathrm{p}_{3 / 2}}$ being 13.6 $\mathrm{eV}$ indicate the +3 oxidation state of iron. ${ }^{48,49}$ The shake-up energy separation of the $2 \mathrm{p}_{3 / 2}$ satellite peak was found to be 7.8 $\mathrm{eV}$ from the main peak, in accordance with literature for $\mathrm{Fe}^{3+}$ compounds (see Table S4 + ), further corroborating the $\mathrm{Fe}^{3+}$ oxidation state. $^{50,51}$
Then the magnetic properties were further explored by SQUID magnetometry on a $30 \mathrm{~nm}$ thick $\mathrm{Gd}_{3} \mathrm{Fe}_{5} \mathrm{O}_{12}$ film. Fig. S8a ${ }^{\dagger}$ presents the field dependent magnetic hysteresis loop $(M-H)$ of the sample at $50 \mathrm{~K}$ with the magnetic field applied along the in-plane direction. From the hysteresis loop, a saturation magnetization $\left(M_{\mathrm{s}}\right)$ of $8.5 \mathrm{emu}^{-1}$, remnant magnetization $M_{\mathrm{r}}$ of $2.86 \mathrm{emu} \mathrm{g}^{-1}$ and coercive field $\left(H_{\mathrm{c}}\right)$ of 130 Oe can be extracted. Compared to $\sim 500 \mathrm{~nm}$ thick sol-gel $\mathrm{Gd}_{3} \mathrm{Fe}_{5} \mathrm{O}_{12}$ films, ${ }^{51}$ our samples show significantly lower $M_{\mathrm{s}}$ and larger $H_{\mathrm{c}}$ values. We attribute this difference to the slight off-stoichiometry identified by RBS and the presence of secondary phases identified by XRD. ${ }^{52}$

The temperature dependent magnetization behavior $(M-T)$ was investigated in the range of $10-350 \mathrm{~K}$ at 5 kOe magnetic field under zero field cooling (ZFC) and field cooling conditions (FC). A rapid decrease of magnetization was observed below $50 \mathrm{~K}$ with temperature increase, then this trend diminished in $50-350 \mathrm{~K}$ with magnetization approaching zero. $\mathrm{Gd}_{3} \mathrm{Fe}_{5} \mathrm{O}_{12}$ bulk material has a typical compensation point at the vicinity of $\sim 300 \mathrm{~K}$ where $\mathrm{Gd}$ and $\mathrm{Fe}$ moments reverse directions and result in the total magnetization crosses zero. In our investigation, no compensation temperature $\left(T_{\text {comp }}\right)$ was observed, see Fig. S8b. $\uparrow$ Shifts in $T_{\text {comp }}$ from the bulk value has been attributed to film off-stoichiometry but also to a thickness/strain effect. Indeed, ultra-thin films can result in a significant rising of $T_{\text {comp. }} .54$

Finally, the synthesis of $\mathrm{Gd}_{x} \mathrm{Fe}_{y} \mathrm{O}_{z}$ films from $\left[\mathrm{Gd}(\mathrm{DPDMG})_{3}\right]$ and $\left[\mathrm{Fe}\left({ }^{\mathrm{i}} \mathrm{pki}\right)_{2}\right]$ precursors is here investigated. The starting recipes are shown in Table 3.

In this case, as the respective binary oxide GPC are very similar $\left(\left[\mathrm{Fe}\left({ }^{\mathrm{i}} \mathrm{pki}\right)_{2}\right] 0.4 \AA\right.$ A per cycle vs. $\left[\mathrm{Gd}(\mathrm{DPDMG})_{3}\right] 0.6 \AA$ A per cycle), simple alternate subcycles was performed (no nanolaminates). Note that alternating the subcycles sequence the final composition of the film is not affected (being 50 : 50 ), which is probably due to the resemblance of the precursor chemistry.

Analogous to $\mathrm{Gd}_{x} \mathrm{Fe}_{y} \mathrm{O}_{z}$ study from $\left[\mathrm{Gd}(\mathrm{DPDMG})_{3}\right]$ and $\left[\mathrm{Fe}(\mathrm{Cp})_{2}\right]$ sources, the samples were attached in different positions in the chamber to study the elemental distribution. Based on the EDX spectra (Fig. S9†), a Gd/Fe ratio map is generated and shown in Fig. 10a. Samples near the gas inlet are identified with $\sim 1 \mathrm{Gd} / \mathrm{Fe}$ cation ratio, the rest of the area is Gd-deficient which is consistent with the high reactivity of $\left[\mathrm{Gd}(\mathrm{DPDMG})_{3}\right]$ and its susceptibility to be depleted near the inlet. In addition, the pulse sequence does not affect the stoichiometry of the films which could be ascribed to the chemistry resemblance between $\left[\mathrm{Gd}(\mathrm{DPDMG})_{3}\right]$ and $\left[\mathrm{Fe}\left({ }^{\mathrm{i}} \mathrm{pki}\right)_{2}\right]$.

In order to evaluate the film crystallinity and phase formation of the $\mathrm{Gd} / \mathrm{Fe} \sim 1$ samples, XRD $\theta-2 \theta$ scan was carried out. In the as-deposited stage the films are amorphous. Upon $800{ }^{\circ} \mathrm{C}$ annealing, two intense reflections are observed at $32-33^{\circ}$, see Fig. 10b. The most intense reflection at $32.5^{\circ}$ agrees well with the main reflection of $\mathrm{Gd}_{3}$ $\mathrm{Fe}_{5} \mathrm{O}_{12}$ phase. Also, weak peaks at $2 \theta$ of $28.5^{\circ}, 36^{\circ}$ and $54^{\circ}$ 
would further support the formation of $\mathrm{Gd}_{3} \mathrm{Fe}_{5} \mathrm{O}_{12}$. The Bragg reflection that appears as a shoulder at $33^{\circ}$ could be attributed to $\mathrm{GdFeO}_{3}, \mathrm{Fe}_{2} \mathrm{O}_{3}$ and $\mathrm{Gd}_{2} \mathrm{O}_{3}$ which hinders an unambiguously identification of this peak. Therefore, the coexistence of $\mathrm{Gd}_{3} \mathrm{Fe}_{5} \mathrm{O}_{12}$ with $\mathrm{GdFeO}_{3}, \mathrm{Fe}_{2} \mathrm{O}_{3}$ and $\mathrm{Gd}_{2} \mathrm{O}_{3}$ is in well agreement with the reported difficulty to stabilize pure phase $\mathrm{GdFeO}_{3} .{ }^{9}$ These films show an homogeneous and smooth surface morphology with surface roughness values of $1 \mathrm{~nm}$ and average grain size of $70 \mathrm{~nm}$, see Fig. S6b.†

From RBS/NRA, the elemental composition was estimated allowing a comparison of the $\mathrm{Fe} / \mathrm{Gd}$ and $\mathrm{M} / \mathrm{O}$ ratio exhibiting values of 0.96 and 0.5 , respectively, see Table $\mathrm{S} 3, \dagger$ consistent with the EDX data presented in Table 3. The level of $\mathrm{C}$ and $\mathrm{N}$ contamination was found to be low with 0.9 at $\%$ and 0.3 at $\%$, respectively. This indicates that the growth mechanisms of the subcycles are not influenced by the different active surface sites. The thin film thickness of $120 \mathrm{~nm}$ was calculated from RBS and it is in good agreement with XRR. However, from the RBS graph it is visible that a gradient of $\mathrm{Gd}$ and $\mathrm{Fe}$ is formed at the interface. This phenomenon could be in part explained because of the initial deposition of $\mathrm{Gd}_{2} \mathrm{O}_{3}$ cycles acting as seeding layer for the garnet. Consequently, the concentration of $\mathrm{Gd}$ at the Si interface is higher, whereas the Fe signal decreases at the low energy edge indicating a decreased Fe concentration in this area. Nonetheless, it is well reported that gadolinium oxide tend to precipitate during the growth of garnet resulting in a gradient depletion along the garnet matrix, ${ }^{54}$ which could also contribute to the compositional gradient identified from the RBS profile spectrum.

Magnetic properties of the $1 \mathrm{Gd}: 1 \mathrm{Fe} \mathrm{Gd}-\mathrm{Fe}-\mathrm{O}$ sample were explored using SQUID magnetometry with the magnetic field applied in the in-plane direction. From the magnetic hysteresis loop at $50 \mathrm{~K}$, a $M_{\mathrm{s}}$ value of $26.7 \mathrm{emu} \mathrm{g}^{-1}, M_{\mathrm{r}}$ of 13.7 emu $\mathrm{g}^{-1}$, and coercive field $\left(H_{\mathrm{c}}\right)$ of $0.036 \mathrm{kOe}$ were observed, Fig. S10a. The magnetization as a function of temperature was investigated at $5 \mathrm{kOe}$ from 5-300 K, Fig. S10b. $\dagger$ The curve shows no phase transitions in this temperature range. Compared to the previous sample prepared from $\left[\mathrm{Gd}(\mathrm{DPDMG})_{3}\right]$ and $\left[\mathrm{Fe}(\mathrm{Cp})_{2}\right]$, here it is observed a slightly stronger $M_{\mathrm{s}}$ although no $T_{\text {comp }}$ is observed. We attribute this different behavior to the existence of Gd gradient composition identified by RBS, Fig. 11, along with the coexistence of $\mathrm{GdFeO}_{3}, \mathrm{Gd}_{2} \mathrm{O}_{3}$ and $\mathrm{Fe}_{2} \mathrm{O}_{3}$ both being already identified in Fig. 10b as key factors on the magnetic behavior of garnet films (Fig. 11). ${ }^{52}$

\section{Conclusions}

We have evaluated the chemical compatibility of tailor-made $\left[\mathrm{Gd}(\mathrm{DPDMG})_{3}\right]$ and $\left[\mathrm{Fe}\left({ }^{\mathrm{i}} \mathrm{pki}\right)_{2}\right]$ and the traditional $\left[\mathrm{Fe}(\mathrm{Cp})_{2}\right]$ precursors to be deposited by an ALD-type approach. Compatible deposition conditions at $250{ }^{\circ} \mathrm{C}$ using ozone as co-reactant and $70 \mathrm{sccm} \mathrm{N}_{2}$ carrier gas flow have been identified and subsequently tested to prepare a series of $\mathrm{Gd}_{x^{-}}$ $\mathrm{Fe}_{y} \mathrm{O}_{z}$ thin films. RBS/NRA analysis helped identifying the metal to oxygen ratio while confirming that ozone ensured a clean reaction of the surface species with complete desorption of the organics. The combination of $\left[\mathrm{Fe}(\mathrm{Cp})_{2}\right]$ with $\left[\mathrm{Gd}(\mathrm{DPDMG})_{3}\right]$ resulted in the formation of garnet $\mathrm{Gd}_{3} \mathrm{Fe}_{5} \mathrm{O}_{12}$ as the main phase while the combination of $\left[\mathrm{Fe}\left({ }^{\mathrm{i}} \mathrm{pki}\right)_{2}\right]$ and $\left[\mathrm{Gd}(\mathrm{DPDMG})_{3}\right]$, led to a mixture of crystalline $\mathrm{Gd}_{3} \mathrm{Fe}_{5} \mathrm{O}_{12}$, $\mathrm{GdFeO}_{3}$, and $\mathrm{Gd}_{2} \mathrm{O}_{3}$ and traces of $\mathrm{Fe}_{2} \mathrm{O}_{3}$, both showing weak magnetization response. Therefore, an ALD-type approach has been successfully used to stabilize garnet thin films mixed with minor oxide secondary phases offering new opportunities to advance in the synthesis of complex compounds, difficult to obtain by traditional deposition techniques. Importantly, thorough understanding of the reaction mechanism during the film growth enabled by the use of in situ characterization tools will be key factors to fully unravel the synthesis of pure phase garnet films.

\section{Conflicts of interest}

There are no conflicts to declare.

\section{Acknowledgements}

This work has been supported through the "Severo Ochoa" Programme for Centres of Excellence in R \& D (CEX2019000917-S), and MAT2017-83169-R from the Spanish Ministry of Economy and Competitiveness. This article is based upon work from COST Action MP1402 "Hooking together European research in atomic layer deposition (HERALD)", supported by COST (European Cooperation in Science and Technology). The authors gratefully thank the Scientific Services at ICMAB and G. Sauthier from ICN2 core support facilities for XPS analysis. This work has been done in the framework of the doctorate in Materials Science of the Autonomous University of Barcelona. We also acknowledge financial support from China Scholarship Council fellowship to P. Yu (201606920073). The authors from RUB thank the DFG-DE-790-11-1 project for partly supporting this project. M. C. acknowledges Beca Leonardo from Fundación BBVA.

\section{Notes and references}

1 S. Geller, J. Chem. Phys., 1956, 24, 1236-1239.

2 M. A. Gilleo, J. Chem. Phys., 1956, 24, 1239-1243.

3 Y. Tokunaga, N. Furukawa, H. Sakai, Y. Taguchi, T. H. Arima and Y. Tokura, Nat. Mater., 2009, 8, 558-562.

4 A. Panchwanee, V. Raghavendra Reddy, A. Gupta, R. Choudhary, D. Phase and V. Ganesan, Thin Solid Films, 2019, 669, 301-305.

5 E. E. Anderson, J. R. Cunningham and G. E. McDuffie, Phys. Rev., 1959, 116, 624-625.

6 Y. Tokunaga, Y. Taguchi, T.-h. Arima and Y. Tokura, Nat. Phys., 2012, 8, 838-844.

7 A. A. Serga, A. V. Chumak and B. Hillebrands, J. Phys. D: Appl. Phys., 2010, 43, 264002. 
8 C. Suchomski, C. Reitz, C. T. Sousa, J. P. Araujo and T. Brezesinski, Chem. Mater., 2013, 25, 2527-2537.

9 N. Kimizuka, A. Yamamoto, H. Ohashi, T. Sugihara and T. Sekine, J. Solid State Chem., 1983, 49, 65-76.

10 M. Bibes, J. E. Villegas and A. Barthélémy, Adv. Phys., 2011, 60, 5-84.

11 M. Coll, J. Fontcuberta and M. Althammer, et al., Appl. Surf. Sci., 2019, 482, 1-93.

12 J. Schmitz, Surf. Coat. Technol., 2018, 343, 83-88.

13 H. H. Sønsteby, E. Skaar, Ø. S. Fjellvåg, J. E. Bratvold, H. Fjellvåg and O. Nilsen, Nat. Commun., 2020, 11, 1-7.

14 M. Ritala and M. Leskelä, in Handbook of Thin Films, Elsevier, 2002, pp. 103-159.

15 S. M. George, Chem. Rev., 2010, 110, 111-131.

16 H. Knoops, S. Potts, A. Bol and W. Kessels, in Handbook of Crystal Growth, Elsevier, 2nd edn, 2015, vol. 3, pp. 11011134.

17 M. Coll and M. Napari, APL Mater., 2019, 7, 110901.

18 M. Lie, O. Nilsen, H. Fjellvåg and A. Kjekshus, Dalton Trans., 2009, 481-489.

19 A. J. M. Mackus, J. R. Schneider, C. MacIsaac, J. G. Baker and S. F. Bent, Chem. Mater., 2019, 31, 1142-1183.

20 J.-H. Kim, J.-Y. Kim and S.-W. Kang, J. Appl. Phys., 2005, 97, 093505.

21 H. H. Sønsteby, H. Fjellvåg and O. Nilsen, Adv. Mater. Interfaces, 2017, 4, 1-15.

22 S. Vangelista, A. Lamperti, C. Wiemer, M. Fanciulli and R. Mantovan, Thin Solid Films, 2016, 604, 18-22.

23 C. Bohr, P. Yu, M. Scigaj, C. Hegemann, T. Fischer, M. Coll and S. Mathur, Thin Solid Films, 2020, 698, 137848.

24 R. G. Gordon, in ALD Precursors and Reaction Mechanisms, ed. C. S. Hwang, Springer, Boston, MA, 2014, pp. 15-46.

25 T. Hatanpää, M. Ritala and M. Leskelä, Coord. Chem. Rev., 2013, 257, 3297-3322.

26 D. Peeters, A. Sadlo, K. Lowjaga, O. Mendoza Reyes, L. Wang, L. Mai, M. Gebhard, D. Rogalla, H.-W. Becker, I. Giner, G. Grundmeier, D. Mitoraj, M. Grafen, A. Ostendorf, R. Beranek and A. Devi, Adv. Mater. Interfaces, 2017, 4, 1700155.

27 A. P. Milanov, R. A. Fischer and A. Devi, Inorg. Chem., 2008, 47, 11405-11416.

28 A. P. Milanov, K. Xu, A. Laha, E. Bugiel, R. Ranjith, D. Schwendt, H. J. Osten, H. Parala, R. A. Fischer and A. Devi, J. Am. Chem. Soc., 2010, 132, 36-37.

29 S. Macke, A. Radi, J. E. Hamann-Borrero, A. Verna, M. Bluschke, S. Brück, E. Goering, R. Sutarto, F. He, G. Cristiani, M. Wu, E. Benckiser, H.-U. Habermeier, G. Logvenov, N. Gauquelin, G. A. Botton, A. P. Kajdos, S. Stemmer, G. A. Sawatzky, M. W. Haverkort, B. Keimer and V. Hinkov, Adv. Mater., 2014, 26, 6554-6559.
30 M. Mayer, Nucl. Instrum. Methods Phys. Res., Sect. B, 2014, 332, 176-180.

31 Y. Wang, M. Dai, M.-T. Ho, L. S. Wielunski and Y. J. Chabal, Appl. Phys. Lett., 2007, 90, 022906.

32 F. Sandiumenge, A. Cavallaro, J. Gàzquez, T. Puig, X. Obradors, J. Arbiol and H. C. Freyhardt, Nanotechnology, 2005, 16, 1809-1813.

33 S. Seppälä, J. Niinistö, M. Mattinen, K. Mizohata, J. Räisänen, W. Noh, M. Ritala and M. Leskelä, Thin Solid Films, 2018, 660, 199-206.

34 J. R. Schneider, J. G. Baker and S. F. Bent, Adv. Mater. Interfaces, 2020, 7, 2000318.

35 H. H. Sønsteby, A. Yanguas-Gil and J. W. Elam, J. Vac. Sci. Technol., A, 2020, 38, 020804.

36 J. Niinistö, N. Petrova, M. Putkonen, L. Niinistö, K. Arstila and T. Sajavaara, J. Cryst. Growth, 2005, 285, 191-200.

37 J. H. Han, A. Delabie, A. Franquet, T. Conard, S. Van Elshocht and C. Adelmann, Chem. Vap. Deposition, 2015, 21, 352-359.

38 B. M. Klahr, A. B. Martinson and T. W. Hamann, Langmuir, 2011, 27, 461-468.

39 A. B. F. Martinson, M. J. DeVries, J. A. Libera, S. T. Christensen, J. T. Hupp, M. J. Pellin and J. W. Elam, J. Phys. Chem. C, 2011, 115, 4333-4339.

40 X. Li, N. C. Fan and H. J. Fan, Chem. Vap. Deposition, 2013, 19, 104-110.

41 A. Devi, Coord. Chem. Rev., 2013, 257, 3332-3384.

42 M. Leskelä and M. Ritala, Angew. Chem., Int. Ed., 2003, 42, 5548-5554.

43 A. Zydor, V. G. Kessler and S. D. Elliott, Phys. Chem. Chem. Phys., 2012, 14, 7954-7964.

44 G. Dey and S. D. Elliott, J. Phys. Chem. C, 2015, 119, 5914-5927.

45 K. L. Pickrahn, A. Garg and S. F. Bent, ACS Catal., 2015, 5, 1609-1616.

46 J. W. Elam and S. M. George, Chem. Mater., 2003, 15, 1020-1028.

47 D. Raiser and J. Deville, J. Electron Spectrosc. Relat. Phenom., 1991, 57, 91-97.

48 E. Paparazzo, Appl. Surf. Sci., 1986, 25, 1-12.

49 A. P. Grosvenor, B. A. Kobe, M. C. Biesinger and N. S. McIntyre, Surf. Interface Anal., 2004, 36, 1564-1574.

50 P. C. J. Graat and M. A. J. Somers, Appl. Surf. Sci., 1996, 100101, 36-40.

51 F. Söderlind, L. Selegård, P. Nordblad, K. Uvdal and P.-O. Käll, J. Sol-Gel Sci. Technol., 2009, 49, 253-259.

52 E. Sawatzky and E. Kay, J. Appl. Phys., 1971, 42, 367-375.

53 E. Sawatzky and E. Kay, J. Appl. Phys., 1968, 39, 4700-4706.

54 M. Oron, I. Barlow and W. Traber, J. Mater. Sci., 1969, 4, 271-281. 